\title{
Preliminary Assessment and Processing of Beach Sands along the River Nile Banks, Northern State, Sudan
}

\author{
Ahmed A.S.Seifelnasr ${ }^{1}$, Eltahir M.M. Magbu $a^{2}$
}

\begin{abstract}
99 Several samples were collected from the beach sands accumulated in many places along the River Nile banks through the northern state, Sudan. The collected samples were subjected to microscopic, X-ray diffraction and chemical analysis. Mineralogical analysis has shown that the mineral components of those samples include magnetite, hornblende, garnet, ilmenite, rutile, zircon and monazite. Several separation techniques were also applied to separate the potential heavy minerals. The obtained results indicated that the tested beach sand samples contain substantial amounts of the potential heavy minerals, especially zircon and monazite.
\end{abstract}

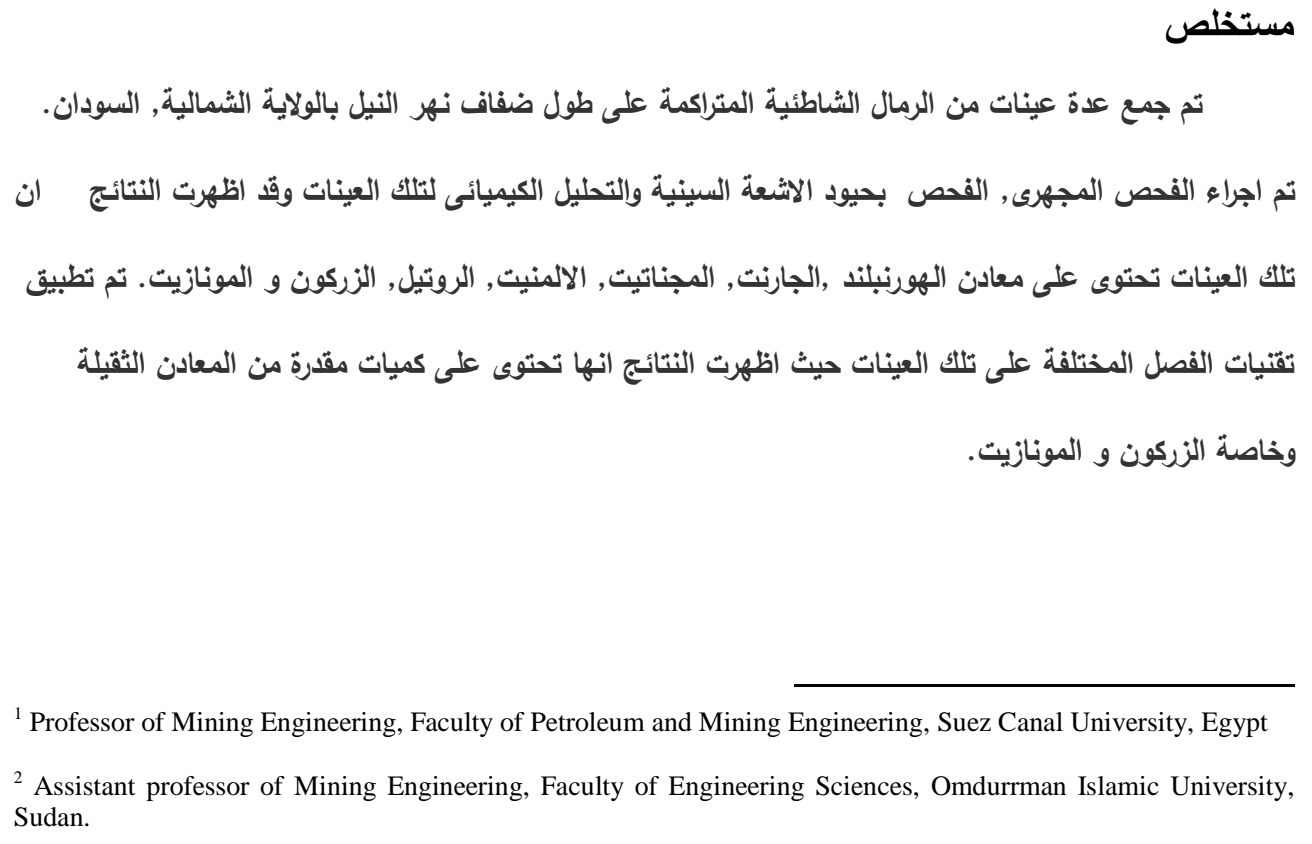




\section{Introduction}

It is known that the black sands have a high economic value and potential industrial uses. This is because it contains the most potential heavy minerals such as, magnetite, ilmenite, rutile, zircon and monazite. Therefore, the evaluation of such material is of particular importance. Ilmenite and rutile are the main sources of the titanium metal which is used as a space age metal due its modest weight, high strength and high resistance to corrosion [1-5]. Moreover, it is used in the industry of paints, paper, rubber, plastics and many other industries. Zircon oxide is used extensively for the manufacturing of firebricks and other minerals exposed to exceptionally high temperature. Zirconium oxide ceramics have low expansion coefficients, high dielectric strengths and are resistant to corrosion by acids, slag and glasses. The thermal stability, resistance to corrosion and low absorption cross section for neutrons of zirconium has led to the extensive use of this metal and its alloys in the construction of nuclear reactors [6-9]. Zirconium metal is also used in the electronic industry as a residual gas getter in vacuum tubes, rectifiers and condensers and in the manufacture of steel.

Monazite (cerium phosphate) is one of the chief minerals of thorium, yttrium and rare-earth ores. Thorium in the monazite is bombarded with slow neutrons in breeder reactors to create fissionable thorium for nuclear fuel cells. The 330-mw high temperature gas-cooled reactor near Platteville Colorado is an example of this operation.

he chief non-energy use for thorium is in the manufacture of Wels beach incandescent gas light mantels. From 20 to $40 \%$ of the produced thorium is 
used as hardener alloy for making magnesium alloys containing 2 to $3 \%$ thorium. Addition of small amounts of thorium oxide to metals such as nickel and tungsten increases their strength and resistance to corrosion.

Therefore, the aim of this study is to persuade the existence of those potential heavy minerals in the accumulated sands along the River Nile banks.

\section{Experimental}

\subsection{Samples}

Four representative grab samples (5kgs.each) were collected from different locations along the River Nile banks from Dongla up to Dologo city.

\subsection{Mineralogical and Chemical Analysis}

Firstly, the samples were subjected to screening process on 250 microns sieve to remove the coarse silica.

Heavy medium separation tests were conducted to separate the light minerals such as quartz and garnet from the heavy minerals. Tetrabromoethane liquid (sp.gr. 2.9) was used as a heavy medium. Certain weight of the samples was introduced into the heavy liquid in a separating funnel. Sufficient time was given for the particles to either settle or float according to its specific gravity. Both float and sink products were finally drained, washed with acetone, dried for 24 hours and then weighed. Samples from the obtained heavy minerals were prepared for examination by the electron microscope. In addition, the samples were ground and then subjected to X-ray Diffract meter to confirm the results obtained by the 
electron microscope. Moreover, the tested feed samples were analyzed chemically. It is worthmentioning, that the above mineralogical and chemical analysis were conducted in central petroleum laboratories (CPL).

\subsection{Heavy Minerals Separation.}

The following processing techniques were performed in the mineral processing laboratory, Faculty of Petroleum and Mining Engineering, Suez Canal University, Suez, Egypt.

Bromoform (sp.gr. 2.89) was used as heavy medium to separate quartz and garnet from the heavy minerals.

How intensity magnetic separator was used to separate the magnetite, then, the high intensity magnetic separator was used to separate the magnetic from the non magnetic minerals. Finally, high-tension separator was used for the treatment of both magnetic and non magnetic fractions. Each fraction was separated into conducting and non conducting minerals.

\section{Results and Discussion}

\subsection{Mineralogical and Chemical Analysis}

Microscopic examination of the tested samples has shown that, almost the same minerals present in all samples. The mineral components include garnet, magnetite, illmenite, zriconite and monazite, rutile, tourmaline and hornblende. Magnetite is the main component of the opaque minerals and it amounts up to $10 \%$. Hornblende is the main component of the transparent minerals and it reaches more than $50 \%$ of the original materials. Moreover, the samples were subjected to X-ray diffraction analysis in order to confirm and assess the quantitative abundance of the valuable heavy minerals in 
those beach sands. The results obtained are shown in Figure (1), which indicate the presence of titanium and zircon oxide. More importantly, monazite was indicated as yitterioum. In addition, the results of the chemical analysis are reported in table (1).

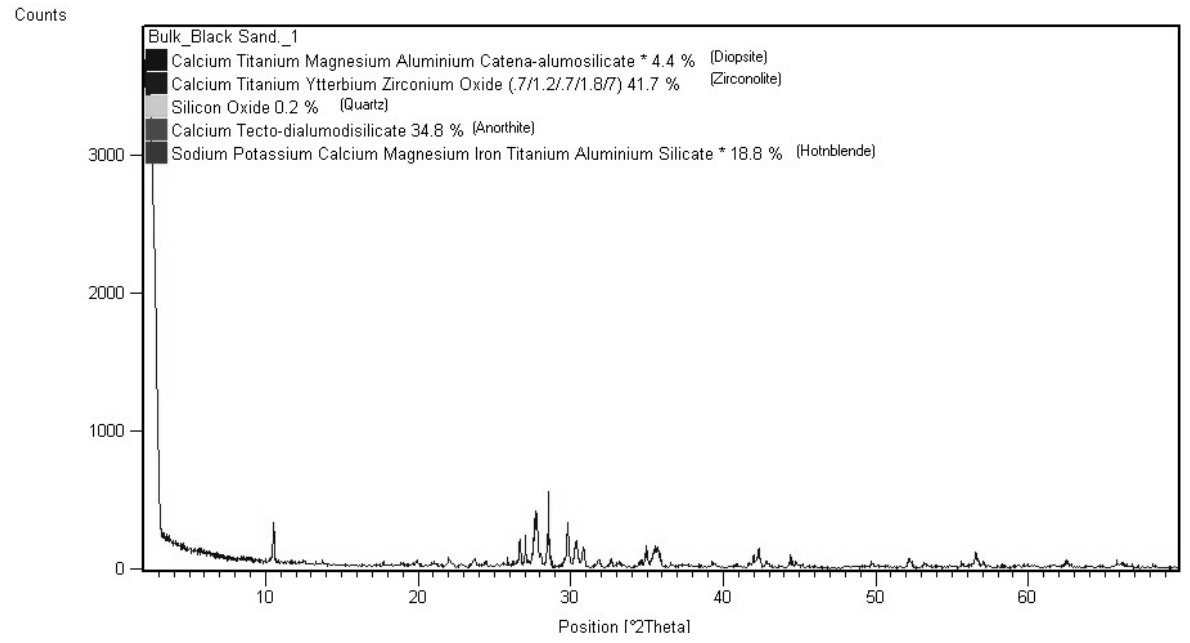

Figure (1): Results of X-ray Diffraction Analysis

Table (1): Chemical Analysis Results.

\begin{tabular}{|c|c|c|c|c|c|}
\hline Mineral & Zriconite & Anorthite & Hornblende & Diopsite & Quartz \\
\hline $\begin{array}{c}\text { Content, } \\
\%\end{array}$ & 41.7 & 34.8 & 18.8 & 4.4 & 0.2 \\
\hline
\end{tabular}

\subsection{Separation of Heavy Minerals.}

The heavy medium separation results indicated that, the amount of heavy minerals was averaging about $43.5 \%$, while the light minerals were $56.5 \%$. The heavy minerals fraction was subjected to low intensity magnetic 
separation to separate the magnetite mineral, which revealed that the magnetite comprising about $10.63 \%$. High intensity magnetic separation was then applied to the magnetite free fraction. The result revealed that the magnetic fraction (persumply containing illmenite and monazite) was $16.21 \%$, while that non magnetic fraction was (persumply containing rutile and zrconite) $16.5 \%$. Finally, each of the magnetic and non magnetic fractions was treated by the high-tension separator to separate the conducting from non conducting minerals. The results of the magnetic fraction indicated about $15 \%$ monazite and $1.2 \%$ illmenite, the non magnetic fraction revealed $12.9 \%$ zrconite and $3.16 \%$ rutile. The following table (2) shows the summary of the obtained results.

Table (2): Results of the Heavy Minerals Separation Using Different Techniques

\begin{tabular}{|l|l|}
\hline Expected mineral & Average content, \% \\
\hline Magnetite & 10.63 \\
\hline Illmenite & 1.21 \\
\hline Rutile & 3.61 \\
\hline Zriconite & 12.9 \\
\hline Monazite & 15 \\
\hline Light minerals (silicates) & 56.5 \\
\hline
\end{tabular}

The results reported in table 2 indicate clearly the abundance of the potential heavy minerals in the given beach sand samples. Also, the results showed that, the zriconite and monazite minerals are the main dominating heavy minerals, thus averaging about $12 \%$ and $15 \%$ respectively. 


\section{Conclusions}

Beach sands occur as superficial batch accumulations along the River Nile through the northern state.

The microscopic examination as well as the X-ray diffraction analysis showed that the beach sands consist mainly of magnetite, illmenite, zircon, rutile, and monazite.

Chemical analyses carried out on the tested samples confirm the abundance of the above potential heavy minerals.

The successive separation technologies were adopted to separate the contained heavy minerals. Thus results in high proportions of magnetite, zircon and monazite.

More extensive research study is needed to further confirmation the existence of heavy minerals and to separate each mineral.

More importantly, studies concerned the precise reserve estimation of these beach sands should be persuade.

\section{References}

[1] Wills, B.A., Mineral processing technology, $7^{\text {th }} . e d$, pergamon press.,Oxford, 2007.

[2] Abdelmageed,A., Sudan industrial minerals and rocks., Center for strategic studies, Khartoum, Sudan.,1988

[3] Hassan, I.E., Heavy mineral studies on beach deposits of delta Tokar Red Sea coast, Ph.D. thesis, University of Brussels., 1986.

[4] Stanley, I.L., Industrial minerals and rocks, SME-AIME., 1983

[5] Elliot,R.A, Beneficiation of titanium ores, with particular reference to Canadian ores. CIM transactions, vol.62, 1959. 
[6] Roberts, J.M.C., Illmenite upgrading, Mining Magazine, vol.125, No. 6, 1971.

[7] Yamada, S., Illmenite beneficiation and its implications for titanium dioxide manufacture, Industrial minerals, No. 100, 1976.

[8] Lewis, R.M., Possible recovery of heavy minerals from phosphate tailings, Preprint No.78B300, SME-AIME Fall eeting, Orlando, FL, 1978

[9] Stamper, J.W., and Chin, E., Zriconium mineral facts and problems, Bulletin 650, US Bureau of mines, 1970a. 